\title{
Infancias/Enfances. Representaciones de la niñez y la juventud en las literaturas de expresión francesa
}

Artal Maillie, Susana G. y Castelló-Joubert, Valeria (comps.) (2017)

Buenos Aires, Dedalus, 210 pp.

\section{Mariana Gómez UBA-CONICET}

Infancias/Enfances. Representaciones de la niñez y la juventud en las literaturas de expresión francesa es una colección de trabajos compilados por Susana G. Artal Maillie y Valeria Castelló-Joubert, que nace a raíz de un proyecto compartido entre la Asociación Argentina de Literatura Francesa y Francófona, el Labo 3 L.AM de l'Université Le Mans (Francia) y la Universidad Laval (Quebec, Canadá), con la colaboración y auspicio del Departamento de Letras de la Facultad de Filosofía y Letras de la Universidad de Buenos Aires.

En el título encontramos ya una declaración de lo que hallaremos en sus páginas: se habla de infancias porque, como se verá a través de los trabajos de los dieciocho investigadores aquí reunidos, no se puede hablar de la infancia, como si se tratase de un único concepto. En diferentes épocas y latitudes, incluso dentro de una misma sociedad, la infancia no es una sola, unívoca e inmutable. Al igual que los niños que habitan su territorio, las infancias son innumerables y nunca permanecen idénticas a sí mismas. Se habla también de enfances porque, como explican Artal Maillie y Castelló-Joubert en la presentación de este libro, el diálogo sostenido entre colegas de quince universidades y dos hemisferios se plasma en la misma pluralidad lingüística de esta compilación: con una única excepción, los trabajos se presentan en la lengua en que fueron escritos.

Y se habla de representación, por supuesto, porque se habla de literatura. "Toda literatura es, por definición, espejo particular y discutible de la compleja realidad, aunque pretenda reflejarla" (p. 13), escribe Fernando Copello (UniversidadLe Mans) en "En torno a los conceptos de representación e infancia", que integra el primer capítulo de este libro. Estas imágenes deformadas nunca se corresponden con el mundo, pero forman nuestras ideas sobre él, trazan (y a veces desdibujan) las fronteras de nuestro pensamiento. Las representaciones de la infancia, al igual que los niños que crecen y se transforman, han mutado a lo largo del tiempo. Desde Platón, quien evoca al niño como ser por moldear, hasta Rousseau, quien reflexiona en torno al niño en cuanto niño y no tanto en cuanto proyecto de hombre, lo cierto es que la niñez no ha sido la misma en todas las épocas ni en todas las latitudes.

¿Qué es lo propio de la infancia, entonces? La infancia, como la literatura, como la risa, es algo propio del ser humano. Es tan variable como la naturaleza humana y toda mirada sobre ella está destinada a ser parcial. Los trabajos de este libro ahondan en las distintas aristas de la reconstrucción de la infancia, le dibujan un contorno pero sin marcarle fronteras definidas: intentarlo sería imposible, como demuestra la multiplicidad de miradas sobre la niñez que se plasman en estas páginas.

Cierra el primer capítulo un trabajo centrado en Víctor Hugo quien, sin ser el primer escritor francés en interesarse en la figura del niño, se destaca por haberle dedicado un lugar privilegiado en su obra. "El niño en la obra de Víctor Hugo. Riqueza de un motivo" es el único de los trabajos escritos originalmente en francés que ha sido traducido al castellano para contrarrestar la falta de bibliografía accesible en nuestra lengua sobre este tema en la obra del autor. En ese artículo, Franck Laurent (UniversidadLe Mans) rastrea el modo en que el motivo del niño acompaña y permite ciertas innovaciones poéticas y literarias y analiza la representación de la niñez en las diferentes dimensiones en que la trabaja Hugo. En la dimensión poética y literaria, el niño aparece como encarnación 
de lo familiar que irrumpe en la poesía con el romanticismo, es una nueva voz, incluso un lenguaje; también simboliza la renovación de la relación literaria con la naturaleza. Laurent estudia, además, el modo en que la naturaleza del niño, siempre cambiante, se relaciona con el uso de la fragmentación y la elipsis en la narrativa hugoliana. El motivo del niño aparece por otra parte en la dimensión política y social, como agente de cambio; y en la dimensión religiosa, con el niño como intercesor entre dos mundos.

"La infancia en la encrucijada" se titula el segundo capítulo, que reúne colaboraciones donde se analizan las representaciones de niños y jóvenes en contextos de conflicto y los modos en que se constituyen las subjetividades en situaciones límite. Amelia Bogliotti (Universidad Nacional de Córdoba) indaga la cuestión de la representación de la infancia y la juventud en tres obras de Bernard-Marie Koltès, donde aparecen tanto niños-jóvenes marcados por el encierro, como los hijos del exilio o la violación, cuya subjetividad está tensionada por relaciones familiares a veces distantes; otras veces, sofocantes y casi siempre, violentas.

Por su parte, Yves Clavaron (UniversidadJean Monnet - Saint Etienne) se centra en las estrategias para expresar lo indecible al intentar representar el genocidio, en su análisis de la novela L'Aîné des orphelins de Tierno Monénembo, en la que el posgenocidio ruandés se articula a partir de la voz de un niño, una voz que se encuentra atravesada por la afasia y la amnesia. Clavaron observa con acierto la relación de la novela con el género picaresco, pero donde la iniciación del pícaro se ve truncada por el horror, el cual solo se puede abordar por sus contornos y nunca directamente. Sofía Criach (Universidad Nacional de Cuyo/Conicet) también se interesa por el retrato de la infancia en el contexto africano, en este caso, en la obra del autor senegalés Boubacar Boris Diop. Criach se concentra en las representaciones de la juventud femenina en Les tambours de la mémoire y en Kaveena, donde la infancia africana aparece como vulnerable y a menudo violentada, pero la llegada de la juventud trae aparejada la posibilidad de la resistencia y hasta de la venganza.

Desde el otro hemisferio, Emilia I. Deffis (UniversidadLaval) estudia en Tas-d'roches, del autor quebequense Gabriel Marcoux-Chabot, cómo el complejo entramado de diversas lenguas y voces pone en escena no solo las tensiones en la conformación de la identidad de su protagonista, sino que manifiesta a su vez la multiplicidad de discursos, no siempre armónicos, que conforman la identidad de Quebec. También pensando en la/s lengua/s como conformación de la identidad, Graciela Ortiz (Universidad
Nacional de Rosario) compara dos novelas de Maryse Condé y Adriana Lisboa para rastrear la búsqueda de la identidad atravesada por la reconstrucción de los recuerdos de la niñez y de la juventud, una reconstrucción signada de manera recurrente por las lenguas: la que se aprende en la primera infancia, la que se adquiere en otras tierras, la que se lee e incluso aquella que es negada y estigmatizada. La identidad se crea así a partir de la lengua, propia o ajena, y los modos de apropiársela. Concluye este capítulo el trabajo de Jean Valenti (Universidadde Saint-Boniface), quien utiliza los conceptos de topos y toposémie para repensar el modo en que aparece la infancia en Malone meurt de Samuel Beckett.

Las literaturas del yo son el foco del tercer capítulo, "La infancia, entre la autobiografía y la autoficción”, en el que los investigadores indagan en los modos de reconstruir la memoria para recuperar la voz infantil. ¿Cómo se captura esa conciencia del pasado desde el presente de quien escribe? ¿Dónde se traza la línea (si es que existe) entre autor y personaje cuando se escribe de un yo, pero el yo que ya no es? Tal como lo plantea Laura Alcoba, escribir de la propia infancia es hablar de lo que sucedió en la niñez "desde la altura de la niña que yo fui" ( $p$. 118). Precisamente en dos novelas de Laura Alcoba, Manèges. Petite histoire argentine y Le bleu des abeilles, Natalia Ferreri (Universidad Nacional de Córdoba/ Conicet) rastrea las formas en que "la autora captura la conciencia de la infancia" (p.122), a partir de la construcción, desde distintos niveles de los biografemas, de la infancia y de un proceso de autoobjetivación, en el cual el yo se configura fuera de sí mismo y se describe la propia infancia como lo ajeno. Ferreri constata la emergencia de una doble conciencia, con la escisión del yo traspuesto en dos voces y en dos tiempos, un rasgo que permite pensar en otras escrituras del yo, con la tensión permanente entre el presente en que se escribe y el pasado que se intenta recuperar. Esta doble conciencia es un hallazgo fundamental a la hora de pensar en las literaturas del yo y, en especial, en la autoficción. Por su parte, en Partir avant le jour de Julien Green, Silvia Nora Labado (Universidad de Buenos AiresUniversidad Nacional de Gral. Sarmiento) estudia la manera en que, aun con la intención de rehuir toda forma de artificio y de cronologización de los recuerdos, la tensión entre el recuerdo y el olvido dota necesariamente de una lógica y de un orden al caos del pasado. Necesariamente, existe una lógica que determina lo que podemos recordar y cuáles son las porciones de nuestro pasado que pueden recuperarse y representarse. 
"Como representación de la memoria, la autobiografía recoge el pasado en que los recuerdos se unen a la imaginación" (p. 133): como señala Graciela Mayet (Universidad Nacional del Comahue), quien escribe sobre sí mismo construye una proyección sobre lo que se cree y se desea ser, y toda recuperación del pasado implica una reinterpretación del presente. En su trabajo sobre Souvenirs pieux de Marguerite Yourcernar, Mayet estudia cómo la autora explicita una distancia entre el ser y el yo al comenzar su autobiografía refiriéndose a "l'être que j'appelle moi» (el ser al que denomino yo) y los modos en que busca reconstruir su propia infancia como si fuera la de un personaje histórico, al retrotraerse a la historia de la infancia y juventud de la madre a la que nunca conoció. Los mismos mecanismos del género autobiográfico son, por otra parte, puestos en cuestión en la obra de Nathalie Sarraute: Claudia Moronell (Universidad Nacional de La Plata) destaca el desdoblamiento de la voz de quien escribe sobre sí mismo y la intención de indagar y analizar los temas que surgen de la escritura de la memoria, la cual prevalece por encima de cualquier tipo de pacto de veracidad y, sobre todo, la imposibilidad de la representación realista aun cuando la escritora se tome a sí misma como personaje en un juego estético y formal.

Todo intento de recuperación de un pasado, propio o ajeno, implica una construcción: en su trabajo sobre Dora Bruder, de Patrick Modiano, Claudia T. Pelossi (Universidad del Salvador) resalta el modo en que el narrador, mientras investiga la historia de la joven judía asesinada en Auschwitz, encuentra o construye en ella a un doble de su propio yo adolescente pero también, en cierta medida, a un doble de su padre. Es muy interesante el modo en que la identificación con este personaje, reconstruido a partir de la investigación, y de la escritura puede producir una identificación del yo pasado, pero además un intento de reconciliación con ese otro que es el padre.

El último capítulo del libro se enfoca en la relación entre infancia y educación, una cuestión que ha aparecido siempre asociada a la del niño, desde las evocaciones de Platón en La República del niño como un ser que se debe moldear hasta el Émile de Rousseau. Este conjunto de trabajos ofrece distintas miradas sobre esa relación, tan cambiante y mutable como la misma idea de infancia. Celia Mabel Burgos Acosta (Universidad de Buenos Aires/Conicet) estudia la tensión entre el niño y la pedagogía: del mundo erotizado y corporal de la niñez que choca con el mundo contemplativo de la adultez en Rabelais a la visión del niño como ser inescrutable y hasta monstruoso en Montaigne, para quien la pedagogía, tras el agotamiento del modelo humanista, no puede ofrecer garantía alguna. Edwige Chirouter (Universidad de Nantes), en cambio, estudia la práctica de la filosofía con los niños que permite pensar en una filosofía de la infancia. Se interesa por la emergencia de una literatura infantojuvenil y la manera en que esta puede tender un puente entre los niños y la filosofía, de modo que puedan pensarse a sí mismos, a los otros y su lugar en el mundo.

Por otra parte, Estefanía Montecchio (Universidad Católica Argentina) analiza, en L'arrache-coeur de Boris Vian, el contraste entre la vejez y la niñez por medio de la figura del puer senex, unión de la juventud con la sabiduría de la vejez, encarnada en el pequeño Citroën. En la escritura de Boris Vian, ciertos sentidos prevalecen en la vejez o la niñez, que parecen degradarse al compararse con este ser que no es ni niño ni viejo, sino una categoría que los supera a ambos.

Los dos trabajos que cierran este volumen toman como eje el clásico de Antoine de Saint-Exupéry, Le Petit Prince, desde diferentes enfoques. Ana María Peña (Universidad Nacional de Salta) retoma el rol simbólico de los animales, en particular la serpiente, y el rechazo al crecimiento que aparece en el retrato desolador que presenta Saint-Exupéry del fin de la infancia. Esta visión pesimista se transmite a su vez en la experiencia pedagógica realizada con alumnos del Colegio Nacional de Buenos Aires que analiza María Albertina Takahashi, en la cual los alumnos realizaron transposiciones en video que arrancan al personaje de su mundo simbólico para introducirlo en el nuestro. Es muy interesante cómo en este caso el foco se encuentra, por una vez, no en la representación de la infancia y la juventud construida desde un punto de vista adulto, sino en la mirada de los adolescentes sobre el mundo de los adultos. Y la mirada que nos devuelven en estas transposiciones es particularmente oscura y pesimista: la pérdida de las ilusiones de la infancia en la transición a la madurez termina en la locura o el suicidio. De este modo, las transposiciones realizadas por los chicos capturan este panorama desolador del abandono de la niñez del que habla Peña en su trabajo.

Infancias/enfances despliega un mapa que permite adentrarse por los distintos puntos cardinales de la literatura francófona, por un territorio familiar pero indefinido a la vez como es el de la representación de la infancia. Con una multiplicidad de perspectivas críticas, Infancias/Enfances demuestra también la inagotable capacidad de la literatura de tender puentes que atraviesen latitudes y épocas. 
